\title{
Dental Stick Dosage Form
}

National Cancer Institute

\section{Source}

National Cancer Institute. Dental Stick Dosage Form. NCI Thesaurus. Code C149430.

Solid single-dose preparation, rod-shaped and usually prepared by compression or molding, intended for dental use. 